\begin{tabular}{c} 
JCEBT, 2(1) Maret 2018 ISSN 2549-6379 (Print) ISSN 2549-6387 (Online) \\
JCEBT \\
ONournal of Civil Engineering, Building and Transportation) \\
Available online http://ojs.uma.ac.id/index.php/jcebt \\
\hline
\end{tabular}

\title{
Analisa Perhitungan Bangunan Dengan Metode Etabs Versi 9.7.2
}

\section{Analysis of Calculation of Buildings with Methods Etabs Version 9.7.2}

\author{
Rudi Alfianto, Dedi Rahmat \\ Program Studi Teknik Sipil, Fakultas Teknik \\ Universitas Medan Area, Indonesia \\ Email : gurusinga.rudi1@yahoo.com
}

\begin{abstract}
Abstrak
Perancangan struktur merupakan unsur yang penting pada pembangunan suatu gedung agar dapat menghasilkan gedung yang kuat, aman, nyaman namun tetap ekonomis.Kemajuan teknologi dibidang ilmu struktur dan konstruksi membuat berbagai bentuk desain bangunan semaki beragam.Beragamnya desain yang ada juga semakin membuat perhitungan dari desain tersebut semakin rumit dan semakin lama untuk di kerjakan.Metodologi penelitian ini dimulai dari studi literatur dan mencari data struktur, perhitungan dan pembebanan sesuai SNI 1726-2002.Setelah dianalisa hasil dari etabs diatas dan di bandingkan dengan konsultan perencana untuk ukuran penampang kolom,sloff,balok,dan pelat lantai tetap sama.

Kata kunci : Etabs, Perencanaan Struktur, Teknologi ilmu struktur.
\end{abstract}

\begin{abstract}
The design of the structure is an important element in building a building in order to produce a strong building, safe, comfortable but still economical. Technological advancements in the field of structural science and construction make various forms of building design more diverse. The diversity of existing designs also makes the calculation of the design more complicated and longer to do. This research methodology starts from the literature study and searches the data structure, calculation and loading according to SNI 1726-2002. After analyzing the results of the above etabs and in comparison with the planner's consultant for column sectional dimensions, the sloff, beams, and floor plates remain the same. Keywords: Etabs.Planning Structure,Technology Structure Science
\end{abstract}

How to Cite: Alfianto, R. Rahmat, D., (2018), Analisa Perhitungan Bangunan Dengan Metode Etabs Versi 9.7.2, 2(1)maret 2018:28-33 


\section{PENDAHULUAN}

Perancangan struktur merupakan unsur yang penting pada pembangunan suatu gedung agar dapat menghasilkan gedung yang kuat, aman, nyaman namun tetap ekonomis. Dalam perancangan struktur suatu gedung bertingkat tinggi, Keamanan merupakan faktor utama yang harus diperhatikan. Gaya lateral maupun aksial harus diperhitungkan agar struktur memiliki ketahanan terhadap gaya-gaya tersebut. Analisis terhadap gaya-gaya dalam struktur diperlukan untuk memperkirakan reaksi yang akan ditimbulkan apabila suatu struktur bangunan dikenai gaya tersebut.

1. Bangunan yang akan dianalisa adalah Gedung kantor 4 lantai Pada Proyek Surya Borneo Industri di kota Pangkalan bun-Kalimantan Tengah.

2. Akan dianalisa dengan metode Etabs $\mathrm{V}$ 9.7 .2

3. Perencanaan ketahanan gempa untuk struktur bangunan gedung menggunakan SNI -1726-2002

4. Perancangan elemen struktur menggunakan SNI-03-2847-2002.

5. Perencanaan beban hidup pada lantai bangunan.

6. Perencanaan beban berat sendiri pada lantai dan atap bangunan.

Dalam perencanaan bangunan tersebut lebih ekonomis, cepat dan benar perencanaanya juga cebih cepat dalam melakukan running analysis untuk bangunan Tinggi sekalipun. Tujuan penelitian ini adalah memperoleh perencanaan yang lebih ekonomis,cepat dan tepat,serta membandingkan dengan konsultan perencana.

\section{METODE PENELITIAN}

Metoda perhitungan dengan cara Takabeya yang disajikan dalam bagian ini adalah menyangkut materi perhitungan untuk portal dengan titik hubung yang tetap dan portal dengan titik hubung yang bergerak ( pergoyangan).

Studi literatur dari buku dan jurnal jurnal yang terkait dengan analis gedung kantor. buku acuan SNI yang dipakai SNI 1726-2002

Pengumpulan data dan informasi tentang bangunan yang dijadikan studi kasus penelitian ini, baik data sekunder maupun data primer. Menghitung beban mati dan beban hidup yang terjadi berdasarkan PPIUG 1983 dan SNI 28472002 sesuai fungsi dan jenis yang terdapat pada data. Menghitung parameter beban gempa berdasarkan SNI 1726-2002 termasuk berat struktur tiap lantai Melakukan pemodelan struktur 3 dimensi sesuai dengan denah dan shop drawing dari gedung tempat studi kasus dengan software ETABS. 
Model yang dibuat harus sesuai Model Struktur dengan keadaan nyata di lapangan agar keadaan riil bangunan nyata terevaluasi secara baik. Model tersebut kemudianya akan dijadikan pembanding dengan hasil dari analisa penelitian yang akan dikerjakan. Melakukan analisis struktur dengan menggunakan softwere ETABS. Analisis ini akan menghasilkan gaya-gaya dalam yang terjadi dan kekuatan masingmasing elemen struktur dai beberapa kominasi yang digunakan. Dari gaya-gaya dalam yang didapat dari analisis struktur dengan menggunkan softwere ETABS maka dapat dihitung kebutuhan dimensi beton, jumlah tulangan longitudinal dan transversal berdasarkan SNI 2847-2002 tentang perencanaan beton structural dengan alur seperti pada gambar 1 .

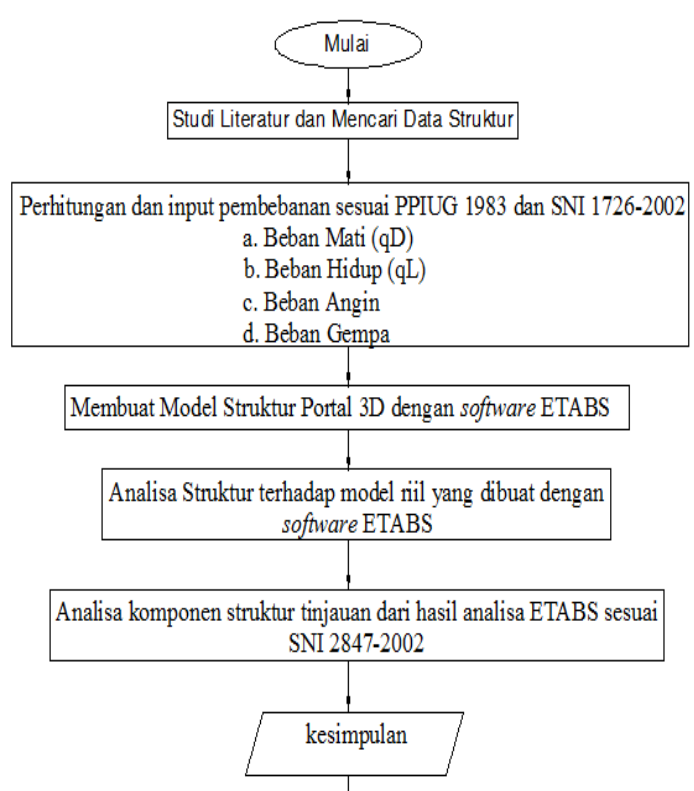

Gambar 1: Diagram Metode Penelitian

Sumber: Etabs Versi 9.7.2
Hasil Dari Etabs Berupa Metode studi kasus berupa pembuatan ulang dengan menggunaan model yang dibuat sesuai kondisi bangunan yang tercantum dalam Rencana Kerja. Input data modeling struktur ke dalam aplikasi Etabs dapat dilihat pada gambar 2 .

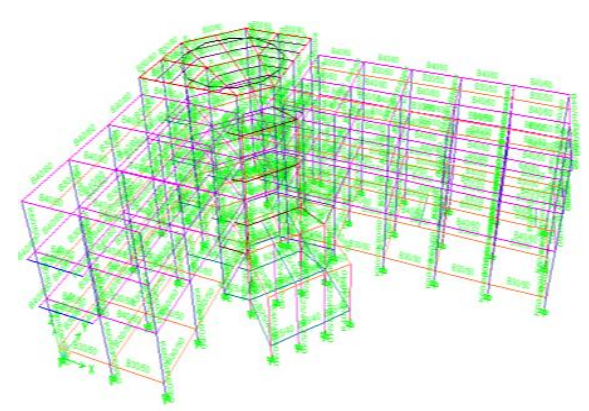

Gambar 2: 3d Bangunan kantor

Sumber :Aplikasi Etabs Versi 9.7.2

Peraturan dan Standar

1. Tata Cara Perencanaan Pembebanan untuk Rumah dan Gedung (SNI 031727-1989-F).

2. Tata Cara Perencanaan Ketahanan Gempa untuk Bangunan Gedung (SNI 03-1726-2002).

3. Tata Cara Perhitungan Struktur Beton Untuk Bangunan Gedung (SNI 032847-1992).
a.Building Code Requirements for Structural Concrete (ACI 318-95)
b. Uniform Building Code (UBC) Input Data Bahan Struktur

Input data bahan struktur ke dalam Etabs seperti pada gambar 3 


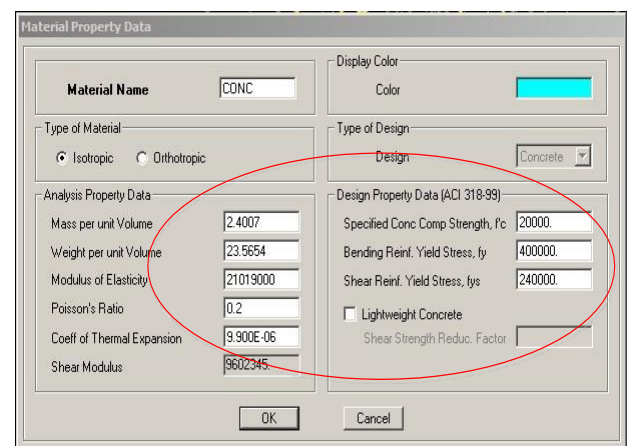

Gambar 3 :Input Bahan Struktur

Sumber : Aplikasi Etabs Versi 9.7.2

Input data bahan struktur penampang seperti pada gambar 4 .

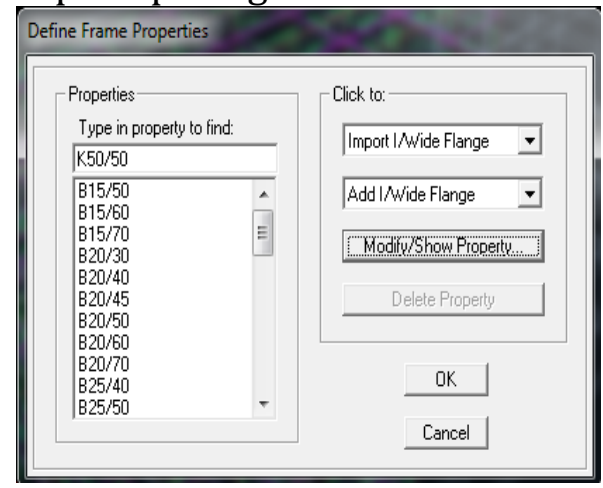

Gambar 4 :Input Dimensi Kolom dan balok Aplikasi Etabs Versi 9.7.2

Input data bahan struktur pelat lantai seperti pada gambar 5 .

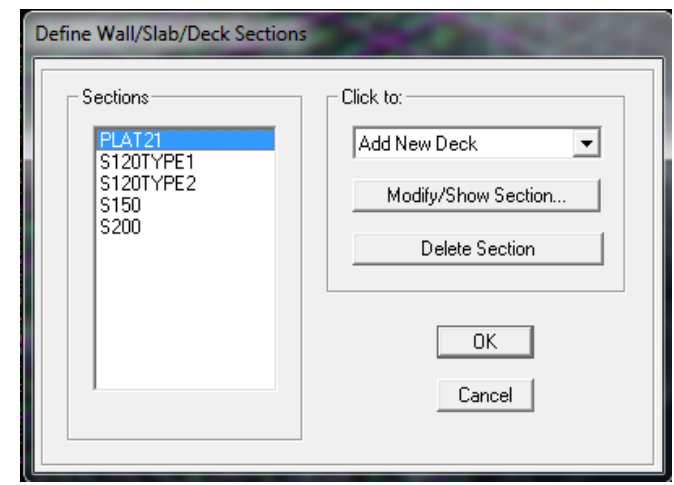

Gambar 5 Input Pelat Lantai Sumber Gambar Aplikasi Etabs Versi 9.7.2

Setelah dimodel dapat dilihat penampang balok pada gambar 6 .

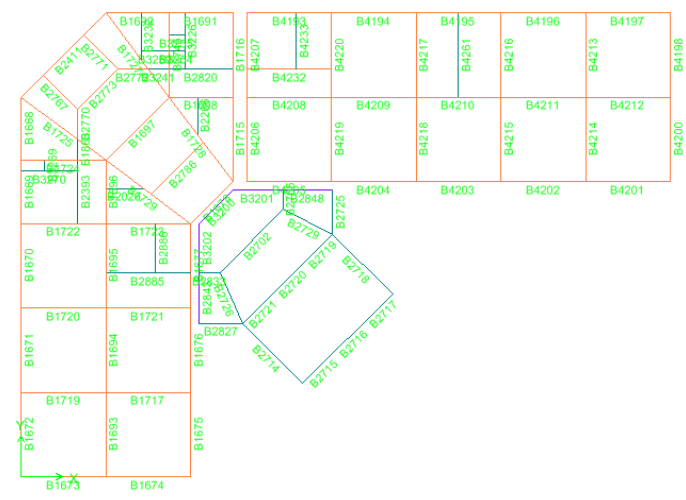

Gambar 6: Denah Balok Elv+o.ooo

Sumber : Aplikasi Etabs Versi 9.7.2

Setelah dimodel dapat dilihat penampang balok pada gambar 7 .

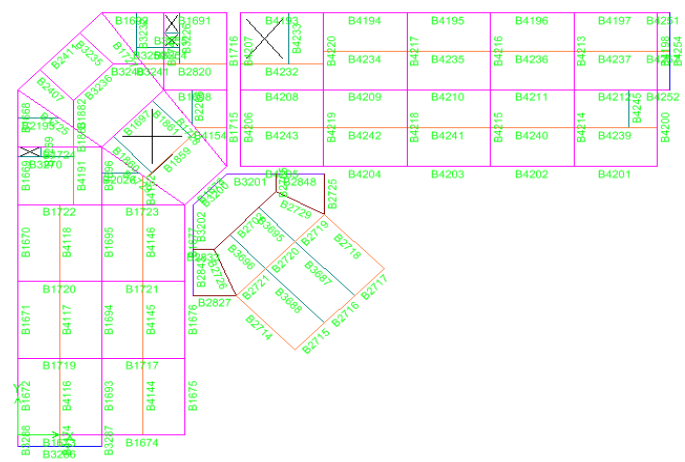

Gambar 7 :Denah Balok Elv+5.500

Sumber : Aplikasi Etabs Versi 9.7.2

Setelah dimodel dapat dilihat

penampang balok pada gambar 8 .

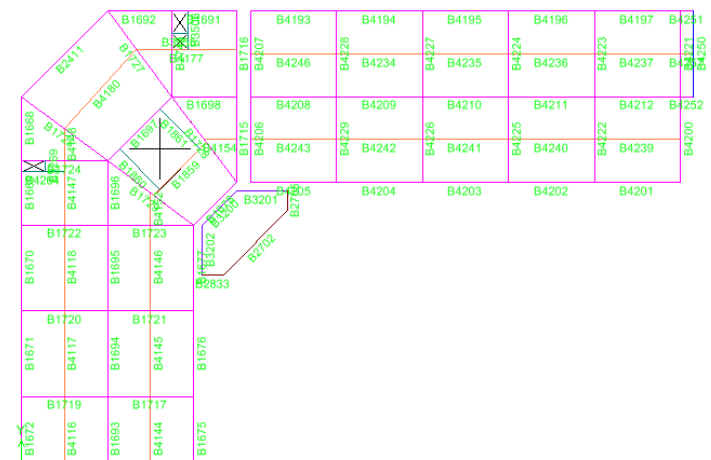

Gambar 8: Denah Balok Elv+9.500

Sumber: Aplikasi Etabs Versi 9.7.2

Setelah dimodel dapat dilihat penampang balok pada gambar 9 . 


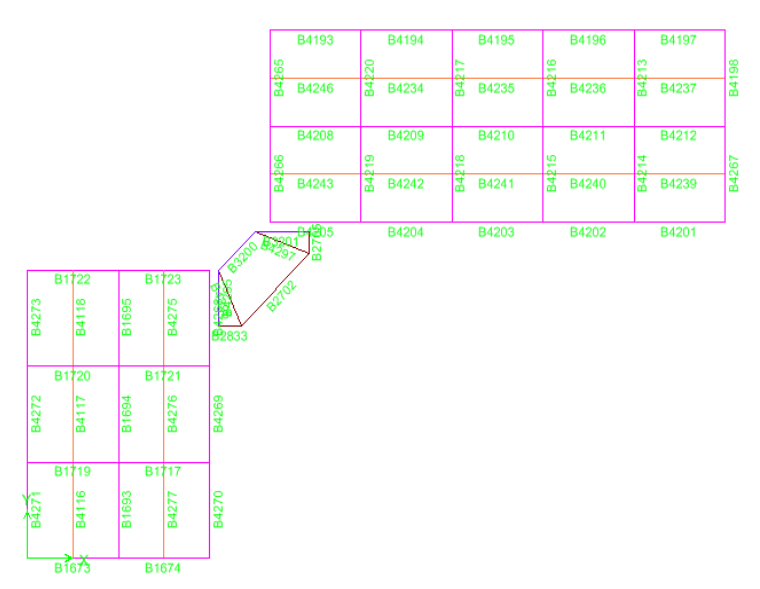

Gambar 9: Denah Balok Elv+13.500 Sumber: Aplikasi Etabs Versi 9.7.2

Setelah dimodel dapat dilihat penampang balok pada gambar 10 .

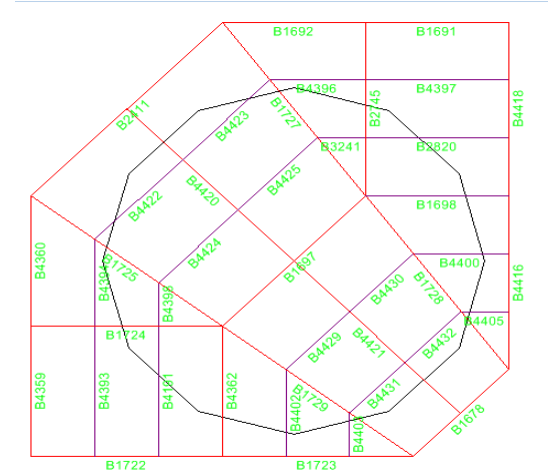

Gambar 1o Denah Balok Elv+15.0oo Sumber: Aplikasi Etabs Versi 9.7.2

\section{SIMPULAN}

Setelah melakukan analisis dan perancangan pada struktur gedung Bangunan Kantor Proyek Surya Borneo Industri di Pangkalan Bun-Kalimantan Tengah. dengan metode Etabs dan telah disesuaikan dengan Tata Cara Perhitungan Struktur Beton Untuk Gedung SNI 03-2847-2002 dan Tata Cara Perencanaan Ketahanan Gempa Untuk Bangunan Gedung SNI 03-1726-2002, dapat diambil simpulan. Perencanaan kontruksi bangunan yang saya teliti dengan metode Etabs versi 9.7.2 hanya memerlukan waktu 3 hari untuk menganalisa bangunan,sangat cepat dibandingkan dengan manual perhitungan bisa memakan waktu 2 sampai 3 bulan. Dalam perancangan gedung ini digunakan pelat dua arah untuk plat atap maupun plat tiap lantai dengan ukuran tebal plat $120 \mathrm{~mm}$ dan 200 mm untuk Pelat lantai Landasan Helipad. Dalam perencanaan balok, digunakan dimensi balok sebesar $300 \mathrm{~mm}$ x 500 mm untuk balok sloff,400 x 600 untuk balok lantai 2 dan 3,dan 500 x 800 untuk balok landasan helipad. Dalam perencanaan Balok - balok tersebut diambil jumlah tulangan lentur dan geser yang paling besar dari tiap Balok-balok. Dalam perencanaan kolom, dimensi yang digunakan untuk kolom sebesar 500 x 500 mm dan 250 x $400 \mathrm{~mm}$. untuk tulangan lentur dan geser diambil yang terbesar dari tiap Kolom-kolom. Balok dimensi awal untuk pemodelan akan diketahui kekuatanya setelah di run dengan Etabs, Bila balok berwarna merah maka penampang perlu diperbesar, Dan sebaliknya bila rasio penampang terlalu kecil maka balok terlalu besar dan masih bisa di perkecil. Setelah dianalisa hasil dari etabs diatas dan di bandingkan dengan konsultan perencana untuk ukuran penampang kolom,sloff,balok,dan pelat 
lantai tetap sama dan ukuranya tidak bisa di

minimkan lagi karna ukuran penampang

sudah ekonomis.

\section{DAFTAR PUSTAKA}

Anugrah Pamungkas dan Erny Harianti, Sesuai SNI 03-1726-2002 dan SNI 03-2847-202, Gedung Beton Bertulang Tahan Gempa Dengan Bantuan Program Etabs V 9.0.7

Badan Standarisasi Nasional. 2002. Tata cara Perencanaan Ketahanan Gempa Untuk Bangunan Gedung (SNI 03 - 1726 - 2002). BSN. Bandung.

Gunawan dan Margareth.1987. Teori Soal dan Penyelesaian Kontruksi Beton 1 Jilid 1. Delta Teknik Group. Jakarta

Ilham., Noer. Analisis Struktur Gedung Bank Bri Aceh dengan ETABS. 2013.Jakarta

Wang, C.K, dan Salmon, C.G. 1990. Desain Beton Bertulang, Jakarta : Penerbit Erlangga, Edisi ke 4 Jilid 1.

Wang, C.K, dan Salmon, C.G. 1990. Desain Beton Bertulang, Jakarta : Penerbit Erlangga, Edisi ke 4 Jilid 2.

Nobel, Afret. 2013. ETABS dalam perencanan Gedung. Yogyakartaamungkas, Anugrah dan Harianti, Erni. 2009. Gedung Beton Bertulang Tahan Gempa. ITS press. Surabaya.

H.R Andrianto, Analisa Struktur Bangunan dengan Etabs versi 9.0.7

Riza., Muhammad Miftakhur,. 2014. Analisa Perencanaan Struktur Gedung Dengan ETABS.Yogyakarta: UGM.

Puskim. (2016, 22 Juli). Desain Spektra Indonesia 2011. Diperoleh 22 Juli, dari http://puskim.pu.go.id/Aplikasi/desain_spe ktra_indonesia_2011/

Budi, Anindito. 2011. Evaluasi Kinerja Seismik Struktur Beton dengan Analisis 